\title{
Modeling and Developing a Learning Design System based on Graphic Organizers
}

\author{
Marco Corbatto \\ SASWEB Lab, DMIF - University of Udine \\ Udine, Italy \\ marco.corbatto@uniud.it
}

\section{THE ISSUE BEING ADDRESSED}

The present research is situated in the area of learning design (LD) systems and computer based tools to support teachers in the delicate task of organizing teaching-learning activities (TLA). A LD system [8] differs from a learning management system (LMS) [10]:

(1) in an LMS the focus is on the organization of a curriculum and on the setting of auxiliary tools to communicate and interact with students;

(2) in an LD the focus is on the design of a course or also of a single teaching session, and on building and assembling TLA in order to create effective learning paths for students. On such a platform, a teacher can arrange the activities, attach appropriate contents and be guided in choosing right tools for the students' tasks.

An open issue is the lack of a Web tool based on graphic organizers to access in a simple way both micro and macro aspects of the LD. The aim of the research is to model a lightweight tool to be used both by teachers and by students as a support for daily learning activities offering attractive interaction and Web access.

\section{MOTIVATION AND RELATED WORK}

This research is prompted by the rapid transformation of methods, roles and practices that are presently involving both primary and high schools. There are many factors contributing to this momentous change: the crisis of the classical teaching approach, especially with the digital native generation of students; the availability of low cost mobile technology and the easy access to global knowledge and information. There are an increasing number of teachers experimenting student centred methodologies.

With this in mind, the planning of activities and experiences proposed to students becomes particularly important as well as the choice of the most effective strategies to improve the learning process. This is a core issue in active learning scenarios where the goal is the development of skills as stated, for example, in the recent Italian school reform and in the European Parliament's recommendations for lifelong learning. Nowadays, the teacher's challenge consists in helping students achieve meaningful learning [5] by means of specific TLA and having them work in their own areas of proximal development, as suggested by Vygotsky.

Permission to make digital or hard copies of part or all of this work for personal or classroom use is granted without fee provided that copies are not made or distributed for profit or commercial advantage and that copies bear this notice and the full citation on the first page. Copyrights for third-party components of this work must be honored

For all other uses, contact the owner/author(s).

UMAP'17 Adjunct, fuly 09-12, 2017, Bratislava, Slovakia

(C) 2017 Copyright held by the owner/author(s)

ACM ISBN 978-1-4503-5067-9/17/07.

https://doi.org/10.1145/3099023.3099028
Today, in many schools, the planning patterns adopted are usually implicit, organized as a list of goals, skills and concepts to be assimilated without any explicit instructions on how to reach the purpose. Very often, the organization of this process is left to the individual teacher and must be delineated at the beginning of each year, without adapting it to the students' actual progresses: the LD is seen as a mere bureaucratic task that teachers have to accomplish.

The LD activity [8] has now become of the utmost importance for the representation and communication of the learning paths to be shared with students and colleagues, with a view to professional growth. In an ideal scenario, LD could be a useful artefact, an educational mediator that provides students with an overall view of their present and possible future, considering both their daily activities and their annual curricula. A more extensive list of tools developed by various research groups is shown in [6].

One of the most comprehensive tool is LAMS (Learning Activities Management System) [7]: it was first developed in 2003, but has evolved considerably up to the present time. LAMS is a Web platform that enables teachers to design, in a very precise way, the single tasks the students will carry out in a specific course, selecting and rearranging them from a set of possible activities.

LAMS is a powerful tool for representing and preparing all the details of a learning path, but it requires a significant effort for the teacher in order to build an entire course or session. Besides, LAMS installation and running is quite complex and does not provide an integrated view of both macro and micro details of the curriculum. Students appreciate it for many characteristics, but sometimes feel constrained by such precise guidance.

Another well known tool is Learning Designer, created by the London Knowledge Lab [12], that offers a Web platform to plan and to fine-tune activities before proposing them to the class as a list of TLAs. Each TLA belongs to one of six categories (read-watch-listen, discuss, investigate, produce, collaborate, practice) and is marked with the description, the amount of time to be allocated for the activity, the number of students per group and the study materials. It is a lightweight environment with the focus only on micro-design.

Some other works: CompendiumLD [1] is a software developed as part of the Open University Learning Design initiative, It enables the creation of learning patterns represented by maps, starting from learning outcomes all the way through to task timing. Unfortunately, it is not Web based.

LD Tool [4] is an initiative of the University of Wollongong, Australia. It is Web based and allows users to define a sequence of tasks, resources, and supports to engage students along a learning path. It is possible to indicate a list of intended learning outcomes.

LD Shake [3][11] is a Web2.0 tool for the social sharing and co-editing of LD solutions. Basically it enables teachers to publish 
planning sheets for lessons and give indications about general planning, educational aspects, single module contents, assessment. It does not provide graphical representation of the learning paths.

Curriculum Mapping [2] is a Web repository of LD based on the national guidelines for Italian schools where teachers can organize learning interdisciplinary paths. The platform doesn't share LDs with students nor provide graphic representations of the paths except for a Gantt diagram of the programmed activities.

\section{METHODOLOGICAL APPROACH AND PRELIMINARY RESULTS}

Some interesting aspects emerged from a preliminary research conducted on a sample of 144 teachers: $85 \%$ consider useful an explicit micro design of the TLAs, but $65 \%$ of them consider it a very time-consuming process; $94 \%$ would appreciate a Web platform to support them in designing the TLA, preferring graphic organizers (71\%) rather than list/tables (25\%); 81\% would prefer a distributed planning activity during the school year and $96 \%$ of then consider very important the simplicity of user interfaces.

The main contributions of this project will be situated in 3 areas:

Modeling entities and functionalities of a Web based LD tool to investigate the most suitable semantic structures to represent the domain information in an LD: for this aspect zz-structures [9] seems to be a promising approach to manage multilevel views. A significant feature is the availability of pedagogical templates to set an initial structure for a design. For example, a teacher could choose a particular methodology (for example Flipped Classroom, EAS, PBL, WebQuest, etc.) to start designing a learning path, having to fill a prebuilt structure instead of starting from scratch. To implement this it will be necessary to analyze the pedagogical structures and map them to the internal semantic model of the LD.

Modeling of suitable visual driven interfaces. There are many different graphic organizers to be taken into account in modeling user interfaces: for instance, hierarchic interactive representations like treemaps, radial trees, circle and sunburst partitions are useful to represent micro and macro scenarios and a collection of hierarchic resources. To express paths and relations it is possible to consider concept maps, Sankey and chord diagrams or narrative charts. For complex information, there are multivariate representations like graphs in different forms or radial charts.

Modeling a repository of Web 2.0 applications to be used both as a recommendation system in the LD and as a stand-alone informative system to guide professionals, students, engineers, administrative workers and so on in discovering the variety of Web applications . Most of these apps have a great potential to improve collaborative, cognitive and creative work: there are hundreds of apps for building rich and attractive digital artefacts and to aggregate heterogeneous materials, to support workgroups, etc. but their effective use in everyday working environments is still very limited.

The main effort during the last months has consisted in the building of a detailed classification scheme that enables us to create a review of 111 (until now) Webapps available on the Internet and to build a substantial database driven by an appropriate taxonomy From a detailed analysis of this set of applications we suggest an initial taxonomy [6] which groups the applications in 3 categories: aggregators, authoring and communication/collaboration tools. At a lower granularity level, we identified 23 subcategories but the cataloging is still going on and the taxonomy will probably grow. It has been observed that many apps have a hybrid characterization so the relation between app and category is multiple; furthermore the multiple relations between an app and the related categories must be weighted to identify the prevalent service offered by the app. For example, many Web application for mindmapping or timeline authoring can offer collaborative editing too, so they can be classified in at least two categories but with different weights to situate the app more precisely in the taxonomy. The Web repository module will constitute a recommender system for teachers who are planning a specific activity for students: based on a brief description of the activity the system will suggest related applications by the use of content-based filtering techniques. An integrated Web platform to discover dedicated and heterogeneous Web 2.0 tools could be of great interest not only for educational purposes but also to increase the productiveness in many professional areas.

\section{EXPECTED OUTCOME AND IMPACT}

To the best of our knowledge, in spite of the extensive research in this area, there is still a lack of suitable and lightweight tools to support the design of educational activities. Furthermore, there is a rapid growth of Web 2.0 apps to create digital artefacts with a strong potential impact in learning activities, and not only: broad sectors of society could benefit from the potential of these tools to improve productivity, especially in the field of new communication media and in the organization of work. The transformation of learning approach into new active forms needs tools to help teachers to organize the work, to make it more effective and sharable in a community of practice. The tools must not load the teachers with new tasks but have to support their creative work and improve the dissemination of good teaching practices.

\section{REFERENCES}

[1] 2017. CompendiumLD learning design. (2017). http://compendiumld.open.ac.uk/ (accessed on March, 21 2017).

[2] 2017. Curriculum Mapping. (2017). http://www.imparadigitale.it/ progetto-curriculum-mapping/ (accessed on March, 21 2017)

[3] 2017. LD Shake: a Web2.0 tool for the social sharing and co-editing of learning design solutions. (2017). http://ldshake.upf.edu/ (accessed on March, 21 2017).

[4] 2017. LD tool learning design collection. (2017). https://needle.uow.edu.au/ldt/ (accessed on March, 21 2017).

[5] D. P. Ausubel. 2012. The Acquisition and Retention of Knowledge: A Cognitive View. Springer Science \& Business Media.

[6] M. Corbatto. 2017. LD Inventory project. (2017). http://sasweb.uniud.it/projects/ LD-Inventory/ (accessed on May, 31 2017).

[7] J. Dalziel. 2003. Implementing learning design: The learning activity management system (LAMS). In 20th Annual Conference of the Australasian Society for Computers in Learning in Tertiary Education. 593-596.

[8] J. Dalziel. 2013. The Larnaca Declaration on Learning Design-Implications for the future. In IEEE 63rd Annual Conference International Council for Educational Media (ICEM).

[9] A Dattolo and F. Luccio. 2009. A formal description of zigzag-structures. In 1st Workshop on New Forms of Xanalogical Storage and Function, CEUR Workshop Proceedings, Vol. 508. 7-11.

[10] R. K.. Ellis. 2009. Field Guide to Learning Management Systems. ASTD Learning Circuits.

[11] D. Hernândez-Leo, P. Moreno, J. Chacôn, and J.. Blat. 2014. LdShake support for team-based learning design. Computers in Human Behavior 37 (August 2014), 402-412.

[12] D. Laurillard, P. Charlton, B. Craft, D. Dimakopoulos, D. Ljubojevic, G. Magoulas, E. Masterman, R. Pujadas, E.A. Whitley, and K. Whittlestone. 2013. A Constructionist Learning Environment for Teachers to Model Learning Designs. Journal of Computer Assisted Learning 29, 1 (2013), 15-30. 